\title{
DISCRIMINAÇÃO RACIAL NO CURRÍCULO DA EDUCAÇÃO BÁSICA BRASILEIRA: ESTUDOS ACADÊMICOS DE 2003 A 2015
}

\author{
RACIAL DISCRIMINATION IN THE BRAZILIAN BASIC EDUCATION CURRICULUM: \\ ACADEMIC STUDIES FROM 2003 TO 2015 \\ DISCRIMINACIÓN RACIAL EN EL CURRÍCULO DE LA EDUCACIÓN BÁSICA \\ BRASILEÑA: ESTUDIOS ACADÉMICOS DE 2003 A 2015
}

Neide Cristina da Silva

E-mail: neidesilva87@hotmail.com

Centro Universitário Drummond / Universidade Nove de Julho - UNINOVE

\begin{abstract}
RESUMO
Muitas têm sido as pesquisas e os estudos sobre a discriminação e o racismo no Brasil. No entanto, salvo os estudos clássicos sobre a escravidão, o tema não tinha muito prestígio nos meios acadêmicos. Após a aprovação da Lei n. ${ }^{\circ} 10.639 / 03$ que instituiu a obrigatoriedade do estudo da história e cultura afro-brasileira no ensino regular, o tema passou a usufruir de maior prestígio entre os pesquisadores das Ciências Sociais e, também, nos estudos educacionais. Partindo dessa premissa e com o intuito de compreender o que pensam os(as) estudiosos(as) acerca da discriminação racial no ensino da disciplina de História na escola básica, a presente pesquisa levantou a produção bibliográfica no período de 2003 a 2015. O estudo foi baseado em pesquisa bibliográfica com consulta aos bancos de teses e dissertações das principais universidades brasileiras. Os resultados demonstraram que as pesquisas concluídas e publicadas sobre o racismo no ambiente escolar ampliam o debate e a reflexão sobre a temática. Entretanto, estão mais voltadas para as práticas docentes e iniciativas institucionais, não refletindo sobre os motivos que levam à perpetuação do racismo no ambiente escolar.
\end{abstract}

PALAVRAS-CHAVE: Ambiente escolar. História do Brasil. Discriminação racial.

\section{ABSTRACT}

There have been many types of research and studies on discrimination and racism in Brazil. However, apart from classical studies on slavery, the topic did not have much prestige in academic circles. After the approval of Law 10.639/03, which instituted the obligation to study Afro-Brazilian history and culture in regular education, the topic started to enjoy greater prestige among researchers in Social Sciences and, also, in educational studies. Based on this premise and in order to understand what scholars think about racial discrimination in the teaching of History in primary school, the present research raised the bibliographic production in the period from 2003 to 2015. The study was based on bibliographic research with the consultation of the thesis and dissertation banks of the main Brazilian universities. The results showed that the completed and published research on racism in the school environment broadened the debate and reflection on the theme. However, they are more focused on teaching practices and institutional initiatives, not reflecting on the reasons that lead to the perpetuation of racism in the school environment.

KEYWORDS: School environment. History of Brazil. Racial discrimination.

\section{RESUMEN}

Ha habido muchos tipos de investigaciones y estudios sobre discriminación y racismo en Brasil. Sin embargo, aparte de los estudios clásicos sobre la esclavitud, el tema no tenía mucho prestigio en los círculos académicos. Luego de la aprobación de la Ley 10.639/03, que instituyó la obligación de estudiar la historia y cultura afrobrasileña en la educación regular, el tema comenzó a gozar de mayor prestigio entre los investigadores en Ciencias Sociales y, también, en los estudios de la educación. Partiendo de esta premisa y con el fin de comprender lo que piensan los académicos sobre la discriminación racial en la enseñanza de la Historia en la escuela 
primaria, la presente investigación planteó la producción bibliográfica en el periodo de 2003 a 2015. El estudio se basó en una investigación bibliográfica con la consulta de los bancos de tesis y disertaciones de las principales universidades brasileñas. Los resultados mostraron que la investigación completada y publicada sobre el racismo en el entorno escolar amplió el debate y la reflexión sobre el tema. Sin embargo, se centran más en las prácticas docentes y las iniciativas institucionales, sin reflexionar sobre las razones que llevan a la perpetuación del racismo en el ámbito escolar.

PALABRAS-CLAVE: Ambiente escolar. Historia de Brasil. Discriminación racial.

\section{INTRODUÇÃO}

Muitas têm sido as pesquisas e os estudos sobre a discriminação e o racismo no Brasil. No entanto, salvo os estudos clássicos sobre a escravidão, o tema não tinha muito prestígio nos meios acadêmicos, possivelmente por causa do mito histórico da "democracia racial brasileira".

Recentemente, com certeza por causa das denúncias do que se poderia chamar de "cripto-racismo" - uma espécie de convicção a respeito da "superioridade racial ariana" inibida pela tragédia nazista da II Guerra Mundial -, o tema racismo passou a usufruir de maior prestígio entre os pesquisadores das Ciências Sociais e, também, nos estudos educacionais. Como se verá a seguir, já há um número razoável de teses e dissertações cujos objetos se inserem no universo da temática, estabelecendo suas relações com os processos educacionais e com o pensamento pedagógico.

Para identificar as contribuições singulares deste estudo, coube a esta pesquisa a reconstituição histórica do que foi produzido academicamente sobre o tema, com o intuito de compreender o que pensam os(as) estudiosos(as) da presença da discriminação racial no currículo da educação básica, o presente artigo apresenta o levantamento da produção bibliográfica, esse levantamento realizou-se como primeira etapa da pesquisa que resultou na tese "O senhor oculto: racismo nos materiais didáticos de história".

\section{MÉTODO}

Com o intuito de compreender o que pensam os estudiosos da presença da discriminação racial na escola básica, foi levantada a produção bibliográfica entre 2003 e 2015, lançando-se mão dos descritores "racismo na escola", "racismo nos livros didáticos", "currículo e relações étnico-raciais", "história e cultura afro-brasileira no ensino básico", "relações étnicoraciais", "prática docente e identidade negra". 
O período escolhido tem como marco inicial o da aprovação e publicação da Lei n. $^{\circ}$ 10.639 em 2003. Como se sabe, essa norma instituiu a obrigatoriedade do ensino de História e Cultura Africana e Afro-brasileira no ensino fundamental e médio, tanto nas escolas públicas como nas particulares e, foi resultado de uma grande luta dos movimentos negros, que desde o período escravocrata sempre teve entre suas bandeiras de luta, o direito à educação. Tanto, que no período pós-abolição, os militantes e os jornais negros, entendiam que para se consolidar a libertação era necessário que todos fossem educados, frequentando as escolas. Apesar disso, "tinha-se a consciência de que, com a educação fornecida pelas escolas, os estudantes negros não deveriam afastar-se da tradição africana, tampouco deixar-se aprisionar-se por ideologias [...] que os afastassem de seu grupo racial" (GONÇALVES; PETROLINA, 2000, p. 143).

O ano de 2015, escolhido como marco cronológico final, assinala os doze anos de vigência da referida lei. Poder-se-ia escolher o ano de 2013, que marca uma década, mas, como se sabe, uma vez aprovada e sancionada, uma lei voltada ao campo educacional leva, em geral, dois anos para "pegar", ou seja, para entrar efetivamente em vigor, na prática, já que os sistemas educacionais exigem, dentre outros fatores, a formação do corpo docente para o ministério dos novos conteúdos, das novas metodologias, ou dos novos procedimentos determinados pelo novo marco legal. Mais tempo ainda leva a atualização dos livros didáticos em relação a toda essa novidade.

Partindo dessa premissa, coube um levantamento nas bases de dados da Coordenação de Aperfeiçoamento de Pessoal de Nível Superior (Capes) e da Biblioteca Digital Brasileira de Teses e Dissertações (BDTD), abrangendo as publicações de dissertação e de teses das diversas instituições públicas e privadas de educação superior do País, para verificar os estudos sobre a temática.

Foram identificadas 25 (vinte e cinco) pesquisas, sendo 17 (dezessete) dissertações e 8 (oito) teses relativas à temática.

\section{REFERENCIAL TEÓRICO}

Por quatro séculos, os africanos, as africanas e seus descendentes foram escravizados(as) e desumanizados(as) no Brasil, dado que os colonizadores lhes negaram o reconhecimento de suas racionalidades e lhes impuseram a cultura do silêncio. No entanto, as 
culturas oprimidas persistiram e resistiram, ainda que perseguidas, humilhadas, desumanizadas. Desenvolveram o "dialeto" da senzala, refugiaram-se nos quilombos, preservaram suas religiões (muitas vezes utilizando uma prática ambivalente que era confundida como cristianização), mantiveram suas tradições em seus corpos e desenvolveram sua própria consciência, sua razão revolucionária. E, em inúmeros períodos da história do Brasil, organizaram-se como classe social e com uma visão de mundo em comum, lutaram pela superação do escravismo moderno no país.

No período colonial e no império ocorreram diversas insurreições dos escravizados, dentre as quais merecem menção:

a) 1807 - Revolta organizada pelos haussás, tendo como chefes principais o liberto Antônio e o escravizado Baltazar;

b) 1809 - Os haussás passaram a trabalhar na organização de novo levante; aliciaram escravizados e libertos de outras nações, como nagôs e gêges;

c) 1814 - Violenta insurreição que tinha como plano sublevar os escravizados das armações, estendendo o movimento ao Recôncavo e, depois, todos reunidos atacariam a cidade de Salvador;

d) 1816 - Teve como campo de ação, os engenhos do Recôncavo em que se concentrava um número avultado de escravizados;

e) 1826 - Em 25 de agosto, revoltosos haviam proclamado um rei e enfrentaram as tropas reinóis, travando combate no qual sofreram numerosas baixas;

f) 1828 - Grande número de nagôs fugiu para as matas e atacaram as armações, saquearam e incendiaram casas;

g) 1829 - Em 26 de outubro, houve nova sublevação dos nagôs do Recôncavo que foi dominada pelos milicianos e moradores;

h) 1830 - Vinte negros saíram pelas ruas da Bahia, promovendo tumulto e assaltando os armazéns, mas o resultado foi que o levante fracassou;

i) 1835 - Freitas (1976) informa que, ao contrário do que o nome da revolução sugere (malês), ela tinha como maioria os insurgentes nagôs, que contaram com elementos de muitas outras nações. Houve uma aliança entre muçulmanos e animistas, a união dos insurretos se deu por motivos políticos (SILVA, 2013).

Evidentemente, as elites se uniram para manter o escravismo por mais tempo, financiando a formação do Estado Burguês com a acumulação de capital proveniente do 
Escravismo Moderno e, depois da abolição da escravidão e da proclamação da República, continuaram impondo a leitura que sua classe social realizava do mundo, pautada em uma visão ocidentocêntrica que desvalorizava e desvaloriza as razões afro-brasileiras e ameríndias, primando por ações antidialógicas e opressoras.

O processo de escravização e exploração do povo negro sempre foi contestado pela população escravizada e por parte dos(as) negros(as) forros(as), sendo possível observar o percurso histórico de combate ao racismo na formação e consolidação da sociedade e do Estado brasileiro, bem como sua identificação e “des-invisibilização". Este reconhecimento se deu, em grande parte, graças à atuação do movimento negro que, nos fóruns internacionais e nacionais, conseguiu desmascarar a ideologia da "democracia racial", forçando o governo brasileiro a manter, na pauta de sua agenda, as questões étnico-raciais.

Deste modo, mais do que livrar-se do domínio político dos colonizadores é necessário romper com a imposição da visão de mundo eurocêntrica, adotando, a partir de uma ação revolucionária, as racionalidades dos povos oprimidos e silenciados ao longo dos últimos séculos. E partindo dos estudos sobre opressão, colonialismo e racismo, optou-se por realizar o levantamento dos estudos sobre temas relacionados ao racismo no ambiente escolar, propondo reflexões de como os acadêmicos e professores discutem e enfrentam o racismo impregnado em todo currículo escolar.

\section{RESULTADOS E DISCUSSÃO}

\section{História Sumária dos Estudos Sobre Relações Étnico-Raciais e Educação Básica}

A partir dos descritores apresentados no item métodos, tem-se os seguintes resultados: concernente ao tema "Racismo no ambiente escolar", tem-se quatro pesquisas, sendo três dissertações de mestrado e uma tese de doutorado:

Mauricio Pereira, na dissertação Racismo na educação: estratégia do Estado e uma possibilidade de superação (2009), realiza um estudo de caso em uma escola localizada no bairro da Casa Verde, na cidade de São Paulo. Analisou como as parcerias entre o referido colégio e as escolas de samba "Unidos do Peruche" e "Morro da Casa Verde" poderiam ter contribuído para a superação do pensamento racista na educação. Constatou que essas parcerias são positivas, porém, insuficientes para a superação do racismo. 
$\mathrm{Na}$ dissertação Uma cartografia da produção do racismo no currículo vivido no cotidiano escolar do ensino fundamental (2011), Sandra Machado realizou um estudo sobre os processos de perpetuação do racismo no ambiente escolar. Para tanto, problematizou as práticas de educadores, entrevistou estudantes e analisou o projeto político-pedagógico de uma escola de ensino fundamental de Vitória, no estado do Espírito Santo (ES). Constatou que o racismo continua presente no cotidiano escolar, pois os estudantes descreveram várias situações de preconceito. Constatou, também, que as questões raciais ainda são discutidas de forma tímida na unidade escolar em questão.

Sandra Bouças desenvolveu uma dissertação intitulada Valores e sentimentos subjacentes à discriminação racial: um estudo na perspectiva dos modelos organizadores do pensamento (2011), em que investigou a representação que estudantes fazem da prática da discriminação racial no ambiente escolar. Para realizar a empreitada, aplicou questionários a 120 (cento e vinte) estudantes de uma escola municipal e de uma estadual, de São Paulo, verificando que existe uma tendência à não reação e tendência a transferir a terceiros a solução das questões de discriminação racial na escola.

A única tese identificada sobre o assunto é Escola e enfrentamento do racismo: as experiências das professoras ganhadoras do Prêmio Educar para a Igualdade Racial (2013), de Maria da Glória Calado, que teve por objetivo analisar os relatos de professoras sobre as práticas pedagógicas premiadas pela 4. ${ }^{a}$ edição do Prêmio Educar para a Igualdade Racial. Investigou as contribuições dessas práticas no enfrentamento do racismo no contexto escolar na educação básica, defendendo que tais práticas pedagógicas estimulam o rompimento do "silenciamento" dos atores escolares.

As pesquisas concluídas e publicadas sobre o racismo no ambiente escolar ampliam o debate e a reflexão sobre a temática. Entretanto, estão mais voltadas para as práticas docentes e iniciativas institucionais, não refletindo sobre os motivos que levam à perpetuação do racismo no ambiente escolar e o porquê, apesar dos avanços propiciados pela Lei $n{ }^{\circ}{ }^{0} 10.639 / 03$, ainda se observa uma negação ou invisibilização da resistência negra ao processo de escravização, assim como, a não problematização da presença de imagens como "A execução do castigo do açoite" de Debret, frequentemente apresentada nos manuais didáticos, que exibe um homem negro humilhado, amarrado, seminu, sendo açoitado por outro negro.

Em uma das dissertações pesquisadas, Sandra Machado (2011) problematiza representações como a de Debret, uma vez que essas envergonham e diminuem a autoestima 
dos(as) estudantes negros e negras, que além de tudo, muitas vezes são apontados pelos(as) colegas de classe como sendo os "mais" racistas, pois batem em seus irmãos. No material didático analisado por Machado (2011), não há referências ao fato de que aquele que está açoitando provavelmente também é escravizado (pois está acorrentado) e, portanto, é obrigado a executar a terrível tarefa delegada por seu senhor, o verdadeiro opressor. Essas e outras práticas presentes no currículo real e no oculto, possivelmente dificultam a assunção da identidade negra pelos(as) estudantes negros(as) das instituições pesquisadas, uma vez que continuam a apresentar o povo negro como subalterno, não contribuindo para a superação do racismo no ambiente escolar.

Com relação ao tema "racismo no livro didático", localizaram-se 5 (cinco) trabalhos acadêmicos: 4 (quatro) dissertações e 1 (uma) tese:

Tatiana Pacífico, na dissertação Relações raciais no livro didático público do Paraná (2011), analisou o livro didático Folhas, com o objetivo de verificar se os livros de Língua Portuguesa e Educação Física atendiam às exigências legais do artigo 26-A da Lei n. ${ }^{\circ}$ 9.394, de 20 de dezembro de 1996, conhecida como Lei de Diretrizes e Bases (LDB), modificada pela Lei n. $\left.{ }^{\circ} 10.639 / 03\right)$. Tentou captar as estratégias ideológicas de hierarquização entre brancos(as) e negros(as) nas políticas públicas e nos livros. Constatou que somente o livro de Educação Física atende, parcialmente e com contradições internas, às determinações legais sobre educação das relações étnico-raciais.

Ribeiro Renilson, na dissertação Colônia (s) de identidades: discurso sobre a raça nos manuais escolares de História do Brasil (2004), realizou um estudo sobre o discurso "raciológico" nas representações da Nação produzidas nos manuais escolares de História do Brasil. Observou que, apesar de as representações dos índios e dos negros ganharem, a cada dia que passa, novas leituras e "vestimentas", ainda não deixaram de ser representados como os "outros", os "exóticos", os "anormais", os "raças inferiores" etc.

Relacionada à temática tem-se ainda a dissertação de Karla Santos, As relações étnicoraciais no livro didático da Educação de Jovens e Adultos (2011), que ao analisar a Coleção dos livros didáticos - LDs adotados pela rede pública de ensino do município de São Miguel dos Campos, estado de Alagoas, identificou que "a presença do povo negro só tem destaque no período colonial e imperial, associado a escravização, humilhação e estigmas de inferioridade" (SANTOS, 2011, p. 108), no período republicano há uma invisibilização das lutas da população 
negra, assim como, dos vários movimentos de resistência que até os dias atuais, lutam por trabalho, saúde, educação e justiça.

De acordo com Santos (2011), a limitação das questões étnico-raciais ao período escravocrata, com ênfase na submissão do povo negro, dificulta a assunção da identidade negra pelos(as) estudantes da EJA e, possivelmente sem a mediação de educadores críticos e comprometidos com a educação antirracista, será muito difícil para os(as) estudantes, superar a visão colonialista e eurocentrada do material em análise.

A última dissertação identificada no período escolhido sobre o tema é a de Andreza Xavier, A imagem do negro em manuais para o professor: uma análise linguístico-discursiva e ideológica (2011), que trata de dois livros paradidáticos do kit de Literatura Afro-Brasileira, elaborados pela rede municipal de ensino de Belo Horizonte (MG). As análises apontaram que, no livro Bonecas negras, cadê?, é construída uma imagem negativa do negro a partir estereótipos inscritos na discriminação que escolhe como categorias a subordinação, a inferioridade e a submissão. Já em Africanidade e afrobrasilidade, a imagem do negro é um pouco mais positiva.

Maria Cristina Pina escreveu a tese $A$ escravidão no livro didático de História do Brasil: três autores exemplares (1890-1930), defendida em 2009. Teve a intenção de perceber o lugar ocupado pelo negro na história do Brasil, concluindo que os livros didáticos foram utilizados para instituir valores e formar adeptos ao projeto de "Nação Liberal", mantendo uma visão hierarquizada entre os grupos raciais.

Em relação ao descritivo "currículo e relações étnico-raciais", foram localizadas 8 (oito) trabalhos acadêmicos: 4 (quatro) de mestrado e 4 (quatro) de doutorado.

Eliana Cruz, na dissertação Percepções das crianças sobre currículo e relações étnicoraciais na escola: desafios, incertezas e possibilidades (2008), teve como objeto o entendimento das crianças sobre as questões étnico-raciais na escola, por meio do currículo explícito. As análises revelaram que as representações mentais das crianças a respeito dos índios e dos africanos ainda são próximas às da época da colonização. No entanto, as crianças percebem a discriminação racial que esses povos vêm sofrendo até os dias atuais.

Deize Ponciano, em sua dissertação História e Cultura Afro-brasileira nos currículos de história do $6 .^{\circ}$ ao $9 .^{\circ}$ anos da rede oficial do estado de São Paulo (2011), analisou como é desenvolvida e apresentada a matéria História e Cultura Afro-Brasileira no currículo. Trata-se 
de uma pesquisa documental, que concluiu que o currículo não remete à situação do afrobrasileiro na sociedade do País.

Na dissertação Etno-identificação na escola: atos de currículo e cultura escolar na construção identitária de estudantes negros (2011), Josevan Soares teve como fim compreender como o currículo escolar pode contribuir para o processo de formação/ressignificação de etnoidentificações. Observou que as questões identitárias estão ausentes no currículo da escola, sendo ele marcado pela descontextualização. Concluiu que o currículo escolar é um produtor de identidades, mas que não está promovendo ressignificação etno-identitária dos estudantes negros.

João Souza, na dissertação Currículo e diversidade étnico-racial na materialidade da Lei 10.639/2003 em duas escolas da rede municipal de Contagem (2011), investigou as práticas curriculares, verificando que o currículo revela influências de relações de poder, tensões e complexidades, não promovendo amplamente a diversidade étnico-racial.

Dentre as teses que tratam do currículo e relações étnico-raciais, Warley da Costa escreveu Currículo e produção da diferença: negro e não-negro na sala de aula de história (2012). A pesquisa teve como objeto os processos de significação e identificação, no currículo de história, dos sentidos de negro/não-negro. A análise evidenciou diferentes fluxos de sentidos nas narrativas dos estudantes, que foram influenciadas pelas práticas pedagógicas desenvolvidas, colocando em debate a discussão sobre a natureza e o papel do conhecimento escolar na construção de uma escola e de uma sociedade democráticas.

Claudia Fortunato, na tese Fios de histórias e memórias dos africanos e afrodescendentes: por uma educação política dos sentidos (2008), teve como objetivo dialogar com os significados da Lei n. ${ }^{\circ}$ 10.639/03 no currículo do Ensino Fundamental e no Médio. Tratou-se de uma pesquisa que recupera memórias sobre o negro no século XIX e que dialoga com a Lei n. ${ }^{\circ}$ 10.639/03. O trabalho empírico demonstrou que o currículo ainda apresenta o outro com exotismo e com caráter folclórico, mas, ao mesmo tempo, que esse tratamento preconceituoso pode ser superado com atividades e processos de conscientização.

A tese $O$ currículo como percurso de reconhecimento da identidade negra (2013), de Sueli Pereira, teve como objetivo analisar as políticas e práticas curriculares do Instituto Federal do Maranhão no que se refere à identidade e ao reconhecimento étnico-racial dos estudantes do Ensino Médio, concluindo que esse Instituto não incorporou uma política nem uma prática curricular que combatem o racismo. 


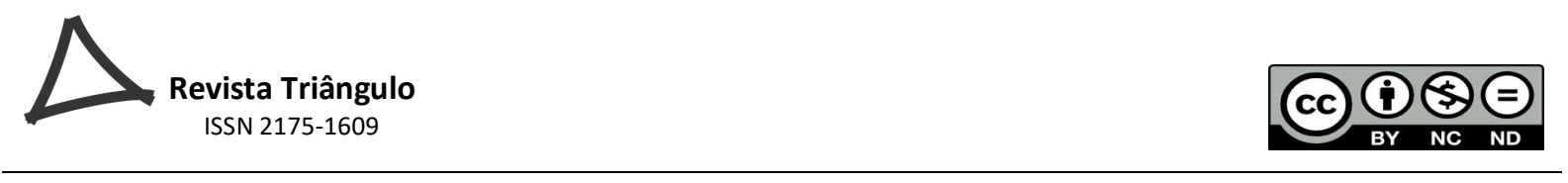

Gizelda Silva elaborou a tese $O$ estudo da história e cultura afro-brasileira no ensino fundamental: currículos, formação e prática docente (2011), questionando se a obrigatoriedade legal do estudo representou rupturas em relação à visão eurocêntrica. A pesquisa aferiu que as escolas das redes privadas estão mais distantes, comparadas às escolas da rede pública, na aplicação da lei.

Como se pode observar, a maioria das pesquisas realizadas, tendo o currículo e as relações étnico-raciais como temática, buscou verificar se ocorreu a efetivação do cumprimento da Lei n. ${ }^{\text {o } 10.639 / 03 ~ n o ~ c u r r i ́ c u l o ~ d o s ~ u n i v e r s o s ~ p e s q u i s a d o s, ~ s e n d o ~ q u e ~ a p e n a s ~ E l i a n a ~ C r u z ~}$ procurou entender como as crianças percebem o racismo. Toda essa importante literatura sobre o tema necessita, porém, a complementação de outros estudos, que busquem, especialmente, compreender como os estudantes e professores percebem o racismo no ambiente escolar e porque após a inclusão de história e cultura africana e afro-brasileira, o racismo ainda persiste expressivamente.

No que se refere às relações étnico-raciais e prática docente, foram identificadas 2 (duas) dissertações e 1 (uma) tese.

Catiani Grellmann realizou, em sua pesquisa, para a elaboração da dissertação Identidade étnica afro-brasileira no ambiente escolar: reflexo da voz docente, a construção da identidade étnica no ambiente escolar (2012), um estudo de caso que envolve o discurso docente. $\mathrm{O}$ resultado das entrevistas demonstrou que os docentes ainda apontam as questões sociais como mais relevantes do que as raciais; que os próprios estudantes negros são preconceituosos e que a opinião dos professores sobre a obrigatoriedade do estudo de história e cultura africana e afro-brasileira ainda é dúbia, pois muitos docentes não enxergam o racismo no ambiente escolar.

José Toniosso, na dissertação Ensino de História e cultura afro-brasileira e africana: da legislação à prática docente (2011), analisa como ocorreu a inserção dessa temática na legislação educacional brasileira, assim como seus reflexos nas práticas docentes na educação básica. A análise dos dados e entrevistas revelou que, ainda que os docentes reconheçam a importância da Lei n. ${ }^{0} 10.639 / 03$, existe uma descrença sobre a sua eficiência na superação do racismo.

A tese Valorização da cosmovisão africana na escola: narrativa de uma pesquisaformação com professoras piauienses, de Rebeca Silva (2012), teve como foco a valorização da cosmovisão africana, no âmbito escolar, em formação de professores. Considerando que os 
docentes não tiveram, em sua formação inicial, valorização da cosmovisão africana, foi realizado um curso de professores no estado do Piauí, nos anos de 2011 e 2012, e a tese em questão procurou analisar as práticas docentes na educação básica após esse curso. Os resultados demonstraram que os docentes reeditaram seus projetos pedagógicos e reviram suas práticas em sala de aula, mostrando-se positiva a formação direcionada para a temática.

Os três estudos referidos demonstraram que existem deficiências na formação inicial dos docentes pesquisados, mas que a formação continuada interfere positivamente na prática docente, no sentido da valorização da história e da cultura afro-brasileira. No entanto, mais uma vez, nenhuma pesquisa estudou a percepção do racismo na prática desses docentes e os motivos de sua permanência, inclusive na prática dos docentes que participaram de cursos de formação continuada sobre o tema.

Referentemente ao descritivo da "identidade negra", foi identificada a dissertação de Pollyana Nicodemos, Sobre construções identitárias de adolescentes negros de classe média: um estudo de caso em uma escola particular de Belo Horizonte (MG) (2011), que objetivou entender o processo de construção identitária de estudantes negros de uma escola da rede privada. Observou que esses estudantes apresentavam aspectos da formação de uma identidade negra. No entanto, apresentam relativa ambiguidade e contradições quando tentavam assumir sua condição negra.

Relativamente à implementação da Lei n. ${ }^{0} 10.639 / 03$ e às relações raciais na escola, foram identificadas 3 (três) dissertações e 1 (uma) tese.

Télia Lopes, com a dissertação Lei $n^{o}$ 10.639/03: um possível caminho para a transformação das relações raciais no espaço escolar (2010), realizou um estudo comparativo entre dois universos, observando que, na escola em que existem projetos que enfatizam os aspectos da história e cultura afro-brasileira, os alunos apresentam posicionamento mais crítico a respeito das relações étnico-raciais, do que no universo em que não foi desenvolvido nenhum projeto específico.

Ana Mendonça desenvolveu a pesquisa Pedagogias antirracistas: tensões e possibilidades de caminhos em construção (2011). Esta dissertação, realizada no universo do Ensino Fundamental I, teve como sujeitos professoras do $4 .^{\circ}$ e do $5 .^{\circ}$ anos. Teve como objeto de estudo a implementação da Lei n. ${ }^{0}$ 10.639/03, como uma legislação de cunho antirracista, buscando compreender como a temática étnico-racial era implementada na escola em questão. Os resultados demonstraram que as professoras evidenciaram a elaboração de táticas voltadas 
para a implementação antirracista, com base no livro didático da disciplina de História, associado ao apoio da equipe gestora, principalmente do supervisor pedagógico, que promove a articulação entre a escola e o movimento negro local.

Christiane Neri, em sua dissertação Identidade negra e reconhecimento: interrogando a Lei n ${ }^{\circ}$ 10.639/03 nas escolas do município de João Pessoa (PB) (2011), analisou o grau de efetividade da referida lei, enquanto ação afirmativa de cunho valorizador dos negros, como meio para a promoção da igualdade racial nas escolas municipais da capital paraibana. Para tanto, realizou entrevistas semiestruturadas com professores, diretores e gestores de cinco escolas do município. A pesquisadora inferiu que existe um discurso de democracia racial entre professores e gestores, que não admitem a discriminação racial, afirmando que o problema é econômico e não racial. Além disso, os professores não veem seu alunado como negros(as), afirmando que a maioria dos estudantes é branca, fato que corrobora a chamada "invisibilidade" do(a) estudante negro(a).

Lana Siman, na tese Saberes e práticas em redes de trocas: a temática africana e afrobrasileira em questão, pesquisa realizada em Contagem (MG) (2010), procurou mapear e analisar os saberes escolares e os saberes e práticas docentes. Priorizou a pesquisa qualitativa e a análise de professores da educação básica. Os resultados apontam para uma dimensão axiológica dos saberes escolares.

Certamente, existem outras pesquisas relacionadas à questão étnico-racial após a implementação da Lei n. ${ }^{\circ}$ 10.639/03.

\section{CONSIDERAÇÕES FINAIS}

Os currículos da educação básica, especialmente os de História da rede de escolas brasileiras ainda adotam a concepção dita "universalista", elaborada pelo Ocidente e que tem como base a história, a organização socioeconômica, as instituições culturais e políticas da Europa.

Partindo dessa constatação a presente pesquisa procurou levantar as publicações sobre história e cultura afro-brasileira, assim como racismo, no currículo da educação básica, considerando o currículo formal, o real e o oculto, entendendo que o reconhecimento do racismo é primordial para consolidar a libertação das mentes colonizadas e, para romper com os estigmas da escravização e subalternização que o povo negro foi submetido ao longo da história. 


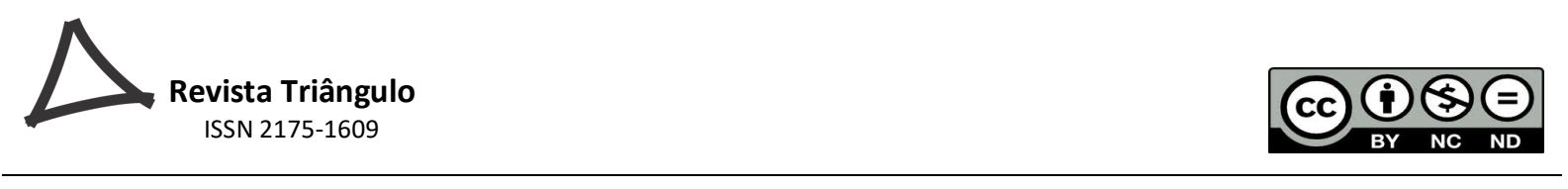

Na revisão de literatura, foi possível observar o percurso histórico do racismo na formação e consolidação da sociedade e do Estado brasileiros, bem como sua identificação e "des-invisibilização". Este reconhecimento se deu, em grande parte, graças à atuação do movimento negro que, nos fóruns internacionais, conseguiu desmascarar a ideologia da "democracia racial", forçando o governo brasileiro a manter, na pauta de sua agenda, as questões étnico-raciais.

No entanto, até a década de 1990, as conquistas não foram substanciais, pois apesar da eleição de um presidente que, por sua trajetória acadêmica, tenderia a implementar ações afirmativas a favor da população negra, elas não ocorreram. O então presidente Fernando Henrique Cardoso e seu ministro da educação Paulo Renato Souza, receberam a proposta do "Programa de Superação do Racismo e da Desigualdade Racial" por ocasião da Marcha de Zumbi em 1995, contudo a atuação desse governo foi tímida e a gestão seguiu defendendo propostas curriculares "universalistas", rejeitando as políticas educacionais baseadas em consciência racial e inclusão. Nesse período, a mídia, intelectuais e até mesmo o governo assumiram um discurso que afirmava ser muito complicado definir quem é negro no Brasil.

Somente no início do terceiro milênio é que a posição do Estado brasileiro foi revista. O governo de Luís Inácio Lula da Silva, em 2003 foi marcado por mudanças nas políticas com perspectivas raciais, merecendo destaque a criação da Secretaria Especial de Promoção da Igualdade Racial (Seppir), do Conselho Nacional de Participação da Igualdade Racial (CNPIR), a aprovação por decreto do Plano Nacional de Promoção da Igualdade Racial (Planapir) e na área da educação, a promulgação da Lei n. ${ }^{\circ}$ 10.639/03 que incluiu no currículo oficial da rede de ensino a obrigatoriedade da temática "História e Cultura Afro-Brasileira", além destas conquistas, pode-se citar a concepção do Programa Universidade Para Todos ( PROUNI ) e o apoio às ações afirmativas nas universidades públicas.

A partir da revisão das teses e dissertações elaboradas de 2003 a 2015, que desenvolveram temas relacionados ao racismo, nos componentes curriculares da educação básica, reflexões sobre as práticas docentes, iniciativas institucionais e formação docente, bem como, a inclusão dos conteúdos de História e Cultura Africana e Afro-Brasileira no currículo, constatou-se que após 13 anos da promulgação da Lei 10.639/03 as práticas docentes ainda precisam ser revistas, os materiais didáticos apesar de incorporar a história e cultura afro, não superaram a divisão eurocêntrica da história e a percepção do racismo pelos docentes ainda é permeada pelo mito da democracia racial. Referente os discentes, de acordo com as pesquisas 
primárias identificadas nas dissertações e teses consultadas, os estudantes, principalmente das escolas privadas têm dificuldade em assumir sua negritude, corroborando com a invisibilidade do povo negro brasileiro.

Desse modo, pode-se afirmar que ainda há um longo caminho a percorrer, no sentido de ultrapassar a visão eurocêntrica do currículo, no qual a população negra é sub-representada, o ensino de história ainda é tradicional e o negro continua associado ao atraso, ao crime e à pobreza.

O caminho é árduo, mas o povo negro tem resistido, tanto é que contrariou a previsão de João Batista Lacerda que, em 1911, no Congresso Universal de Raças, em Londres, previu a extinção dos negros até 2012 e, hoje, a população negra representa 53,6 \% dos brasileiros. E como o caminho se faz caminhando e a despeito das limitações atuais na implementação dos marcos legais a favor da educação para as relações étnico-raciais, estes marcos são conquistas da população negra e precisam ser reforçados, tendo a educação formal e não formal o dever ontológico de aliar-se no combate ao racismo.

\section{REFERÊNCIAS}

BRASIL. Lei n. ${ }^{\circ} 10.639$ de 09 de janeiro de 2003: altera a Lei ${ }^{\circ}$ 9.394, de 20 de dezembro de 1996, que estabelece as diretrizes e bases da educação nacional, para incluir no currículo oficial da rede de ensino a obrigatoriedade da temática História e Cultura Afro-Brasileira, e dá outras providências. Brasília, DF, 2003. Disponível em: $<$ http://www.planalto.gov.br/ccivil_03/leis/2003/110.639.htm>. Acesso em: 24 jun. 2014.

BOUÇAS, Sandra Regina da Silva Brugnoli. Valores e sentimentos subjacentes à discriminação racial: um estudo na perspectiva dos modelos organizadores do pensamento. 2011. 148 f. Dissertação (Mestrado) - Programa de Pós-Graduação em Educação, Universidade de São Paulo, São Paulo, 2011.

CALADO, Maria da Glória. Escola e enfrentamento do racismo: as experiências das professoras ganhadoras do Prêmio Educar para a Igualdade Racial. 2013. 217 f. Tese (Doutorado) - Programa de Pós-Graduação em Educação, Universidade de São Paulo, São Paulo, 2013.

COSTA, Warley da Costa. Currículo e produção da diferença: negro e não negro na sala de aula de história. 2011. 302 f. Tese (Doutorado) - Programa de Pós-graduação em Educação, Universidade Federal do Rio de Janeiro, Rio de Janeiro, 2011.

CRUZ, Eliana Marques Ribeiro. Percepções das crianças sobre currículo e relações étnicoraciais na escola: desafios, incertezas e possibilidades. 2008. 154 f. Dissertação (Mestrado) - 
Programa de Pós-graduação em Ciências Humanas, Universidade Federal de São Carlos, São Carlos, 2008.

FORTUNATO, Cláudia Regina Alves do Prado. Fios de histórias e memórias dos africanos e afrodescendentes: por uma educação politica dos sentidos. 2008. 97 f. Tese (Doutorado) Programa de Pós-graduação em Educação, Universidade Estadual de Campinas, Campinas, 2008.

FREITAS, Décio. Insurreições escravas. Porto Alegre: Movimento, 1976.

GONÇALVES, Luiz Alberto; PETROLINA, Beatriz Gonçalves e Silva. Movimento Negro e educação. Revista Brasileira de Educação. Rio de Janeiro. n. 5, p.134-158, Set.-Dez.2000.

GRELLMANN, Catiani Renata Salvati. Identidade étnica afro-brasileira no ambiente escolar: reflexos da voz docente. 2012. 112 f. Dissertação (Mestrado) - Programa de Pósgraduação em Educação, Universidade de Santa Cruz do Sul, Santa Cruz do Sul, 2012.

MACHADO, Sandra Maria. Uma cartografia da produção do racismo no currículo vivido no cotidiano escolar do ensino fundamental. 2011. 185 f. Dissertação (Mestrado) - Programa de Pós-graduação em Educação, Universidade Federal do Espírito Santo, Vitória, 2011.

MARINHO, Andrea Rodrigues Barbosa. Paulo Freire e a conscientização. 2015. 166 f. Tese (Doutorado) - Programa de Pós-graduação em Educação, Universidade Nove de Julho, São Paulo, 2015.

MENDONÇA, Ana Paula Fernandes. Pedagogias antirracistas: tensões e possibilidades de caminhos em construção. 2011. 147 f. Dissertação (Mestrado) - Programa de Pós-graduação em Educação, Universidade Federal de Viçosa, Viçosa, 2011.

NERI, Christiane Soares Carneiro. Identidade negra e reconhecimento: interrogando a Lei $\mathrm{n}^{\mathrm{o}}$ 10.639/03 nas escolas do município de João Pessoa (PB). 2011. 148 f. Dissertação (Mestrado) - Programa de Pós Graduação em Ciências Jurídicas, Universidade Federal da Paraíba, João Pessoa, 2011.

NICODEMOS, Pollyana Alves. Sobre construções identitárias de adolescentes negros de classe média: um estudo de caso em uma escola particular de Belo Horizonte (MG). 2011. 154 f. Dissertação (Mestrado) - Programa de Pós-graduação em Educação, Pontifícia Universidade Católica de Minas Gerais, Belo Horizonte, 2011.

PACÍFICO, Tania Mara. Relações raciais no livro didático público do Paraná. 2011. 152 f. Dissertação (Mestrado) - Programa de Pós-Graduação em Educação, Universidade Federal do Paraná, Curitiba, 2011.

PEREIRA, Mauricio. Racismo na educação: estratégia do Estado e uma possibilidade de superação. 2009. 160 f. Dissertação (Mestrado) - Programa de Pós-graduação em Educação, Pontifícia Universidade Católica de São Paulo, São Paulo, 2009. 
PEREIRA, Sueli Borges. O currículo como percurso de reconhecimento da identidade negra: políticas e práticas curriculares no Instituto Federal de Educação, Ciência e Tecnologia do Maranhão (IFMA); Campus Monte Castelo. 2013. 318 f. Tese (Doutorado) - Programa de Pós-graduação em Educação, Pontifícia Universidade Católica de São Paulo, São Paulo, 2013.

PINA, Maria Cristina. A escravidão no livro didático de História do Brasil: três autores exemplares (1890-1930). 2009. 220 f. Tese (Doutorado) - Programa de Pós-graduação em Educação, Universidade Estadual de Campinas, Campinas, 2009.

PONCIANO, Deize Denise. História e Cultura Afro-brasileira nos currículos de história do $^{\circ}$ ao $^{\circ}$ anos da rede oficial do Estado de São Paulo. 2011. 102 f. Dissertação (Mestrado) - Programa de Pós-graduação em Educação, Universidade do Oeste Paulista, Presidente Prudente, 2011.

RENILSON, Ribeiro Rosa. Colonia(s) de identidades: discurso sobre a raça nos manuais escolares de História do Brasil. 2004. 421 f. Dissertação (Mestrado) - Programa de PósGraduação em História, Universidade Estadual de Campinas, Campinas, 2004.

SANTOS, Karla de Oliveira. As relações étnico-raciais no livro didático da Educação de Jovens e Adultos: implicações curriculares para uma sociedade multicultural. 2011. $124 \mathrm{f}$. Dissertação (Mestrado) - Programa de Pós-graduação em Educação, Universidade Federal de Alagoas, Maceió, 2011.

SILVA, Daniel B. D. Dossiê Tráfico de Escravos: cálculos de risco. Revista de História da biblioteca nacional. Rio de Janeiro, n. 108, p. 16-45, 2014.

SILVA, Gizelda Costa da. O estudo da história e cultura afro-brasileira no ensino fundamental: currículos, formação e prática docente. 2011. 212 f. Tese (Doutorado) Programa de Pós-graduação em Educação, Universidade Federal de Uberlândia, Uberlândia, 2011.

SILVA, Neide Cristina da. Resistência na casa grande: história e cultura afro na educação de adultos. 2013. 167 f. Dissertação (Mestrado) - Programa de Pós-graduação em Educação, Universidade Nove de Julho, São Paulo, 2013.

SILVA, Rebeca de Alcântara. Valorização da cosmovisão africana na escola: narrativa de uma pesquisa-formação com professoras piauienses. 2012. 195 f. Tese (Doutorado) - Programa de Pós-graduação em Educação Brasileira, Universidade Federal do Ceará, Fortaleza, 2012.

SIMAN, Lana Mara de Castro. Saberes e práticas em redes de trocas: a temática africana e afro-brasileira em questão, pesquisa realizada em Contagem (MG). 2010. 334 f. Tese (Doutorado) - Programa de Pós-graduação em Educação, Faculdade de Educação, Universidade Federal de Minas Gerais, Belo Horizonte, 2010.

SOARES, Josevan Chagas. Etno-identificação na escola: atos de currículo e cultura escolar na construção identitária de estudantes negros. 2011. 145 f. Dissertação (Mestrado) - Programa de Pós-graduação em Educação, Universidade Federal da Bahia, Salvador, 2011. 
SOUZA, João Carlos Pio de. Currículo e diversidade étnico-racial na materialidade da Lei 10.639/2003 em duas escolas da rede municipal de Contagem. 2011. 171 f. Dissertação (Mestrado) - Programa de Pós-graduação em Educação, Pontifícia Universidade Católica de Minas Gerais, Belo Horizonte, 2011.

TONIOSSO, José. Ensino de História e cultura afro-brasileira e africana: da legislação à prática docente. 2011. 167 f. Dissertação (Mestrado) - Programa de Pós-graduação em Educação, Centro Universitário Moura Lacerda, Ribeirão Preto, 2011.

XAVIER, Andreza Santos. A imagem do negro em manuais para o professor: uma análise linguístico-discursiva e ideológica. 2011. 176 f. Dissertação (Mestrado) - Programa de Pósgraduação em Estudos Linguísticos, Universidade Federal de Minas Gerais, Belo Horizonte, 2011. 